\title{
Cinética de absorção de amônio e efluxo de prótons em variedades de milho ${ }^{1}$
}

\section{Ammonium uptake kinetics and protons efflux in corn varieties}

\author{
Eliane de Almeida Borges ${ }^{2}$; Arcângelo Loss ${ }^{3 *}$; Edmilson Evangelista da Silva ${ }^{4}$; \\ Sonia Regina de Souza ${ }^{2}$; Manlio Silvestre Fernandes ${ }^{5}$
}

\section{Resumo}

A análise dos parâmetros cinéticos de absorção de íons $\left(\mathrm{NO}_{3}^{-}\right.$e $\left.\mathrm{NH}_{4}^{+}\right)$é o principal procedimento experimental para a diferenciação da eficiência de absorção desses nutrientes entre espécies e variedades de milho. Este trabalho objetivou avaliar parâmetros relativos à cinética de absorção do amônio e o desempenho metabólico de variedades de milho em ambientes com alta e baixa disponibilidade de nitrogênio. As variedades testadas foram: Catetão, Sol da Manhã, Eldorado e BR 473. O experimento foi conduzido em casa de vegetação e as plantas foram cultivadas em vasos com soluções 1,43 e $8,57 \mathrm{mM}$ de $\mathrm{N}$.Aos 28 dias após germinação determinaram-se os parâmetros cinéticos $\mathrm{V}_{\max }$ e $\mathrm{K}_{\mathrm{M}}$, e na fração hidrossolúvel, quantificou-se $\mathrm{N}$-amino, nitrato e amônio. Obteve-se a massa fresca da parte aérea e de raiz e, seguido com determinação do N-total, P e Mg no material seco. A variedade Sol da Manhã apresentou maior desenvolvimento de sistemas de absorção de alta afinidade, enquanto, as variedades Catetão e Eldorado mostraram maior desenvolvimento para sistemas de baixa afinidade e alta capacidade de absorção de $\mathrm{N}-\mathrm{NH}_{4}^{+}$. A variedade Sol da Manhã apresentou maior adaptação do sistema de absorção à condição de menor disponibilidade de nitrogênio. Os valores obtidos para os parâmetros cinéticos como $\mathrm{V}_{\max }$ e $\mathrm{K}_{\mathrm{M}}$ confirmam o alto potencial produtivo desta variedade descrita na literatura como eficiente no uso de nitrogênio.

Palavras-chave: Disponibilidade de nitrogênio, sistemas de transporte, parâmetros cinéticos, Zea mays $\mathrm{L}$.

\footnotetext{
Abstract

The analysis of kinetic parameters for absorption of ions $\left(\mathrm{NO}_{3}^{-} \mathrm{e} \mathrm{NH}_{4}^{+}\right)$is the main experimental procedure for the differentiation of the efficiency of absorption of these nutrients between corn species and cultivars. This work had the aim of evaluating the kinetic parameters of ammonium uptake to elucidate metabolic strategies of corn cultivars at environments with low and high nitrogen concentrations. The selected cultivars were: Catetão, Sol da Manhã, Eldorado and BR 473. The plants were cultivated in pots with $\mathrm{N}$ solutions of 1.43 and $8.57 \mathrm{mM}$ at green house conditions. The following kinetic parameters were evaluated 28 days after germination: $\mathrm{V}_{\max }, \mathrm{K}_{\mathrm{M}}$ and $\mathrm{N}$-amino soluble fraction in the water, nitrate and ammonium. Fresh mass of above groud part and roots, and $\mathrm{N}$-total, $\mathrm{P}$, and $\mathrm{Mg}$ in the dried material were determined. Sol da Manhã cultivar presented high development at high affinity uptake systems,

1 Parte da tese de Doutorado do primeiro autor apresentada ao Curso de Pós-Graduação em Agronomia - Ciência do Solo (CPGACS) - Universidade Federal Rural do Rio de Janeiro (UFRRJ) - Seropédica, RJ.

2 Professora Associada do Departamento de Química, Instituto de Ciências Exatas da UFRRJ. Caixa Postal 74505. Seropédica/

3 Doutorando do CPGA-CS da UFRRJ. Bolsista CNPq. BR 465, km 07 - CEP: 23890-000 E-mail: arcangeloloss@yahoo.com.

4 Doutorando em Fitotecnia da UFRRJ. Caixa Postal 74505, CEP: 23890-000. Seropédica/RJ.

5 Professor do Departamento de Solos da UFRRJ. Caixa Postal 74505. Seropédica/RJ.
} RJ. br.

Autor para correspondência. 
while Catetão and Eldorado cultivars presented high development at the low affinity and high capacity of $\mathrm{NH}_{4}^{+}$uptake system. Sol da Manhã cultivar presented high adaptation at low nitrogen availability conditions. The values of $\mathrm{NH}_{4}^{+}$uptake kinetic parameters, $\mathrm{V}_{\max }$ and $\mathrm{K}_{\mathrm{M}}$ can justify the high productivity of this cultivar described in the literature as efficient in nitrogen use.

Key words: Nitrogen availability. Transport systems. Kinetic parameters. Zea mays.

\section{Introdução}

A capacidade das membranas de células vegetais em regular a absorção de solutos tem fascinado os botânicos desde o século dezenove. Entretanto, as técnicas experimentais até então disponíveis, limitavam as investigações destes processos e somente a partir do grande desenvolvimento tecnológico ocorrido após a segunda metade do século vinte, alguns esclarecimentos sobre a permebilidade das membranas a diferentes solutos começaram a surgir.

A absorção de íons pelas plantas teve em Epstein e Hagen (1952) o desenvolvimento de trabalhos pioneiros a caminho do esclarecimento de seu mecanismo e sua regulação. Estes pesquisadores relacionaram à cinética da ação enzima e substrato proposta por Michaelis e Menten (1913) ao transporte de íons na membrana de células vegetais, comparando os carreadores de íons a uma molécula de enzima e, os íons, ao substrato. Assim, a velocidade de transporte de um íon através da membrana estaria associada a dois fatores: $\mathrm{V}_{\max }$ - Fator indicativo da velocidade máxima quando todos os sítios de ligação estariam saturados; $\mathrm{K}_{\mathrm{M}}-$ Constante de Michaelis, equivalendo a concentração de íons em que ocorreria a metade da $\mathrm{V}_{\max }$. Portanto, seu valor refletiria o grau de afinidade entre o íon e o carreador.

Dados descrevendo a absorção de amônio foram preliminarmente publicados por Becking (1956) trabalhando com raízes de milho. O influxo de $\mathrm{NH}_{4}^{+}$ em raízes intactas de plantas, que é dependente da concentração externa do íon, exibe uma cinética bifásica que pode ser separada em dois modelos distintos: um saturável de alta afinidade que é predominante em baixas concentrações externas de
$\mathrm{NH}_{4}^{+}$, e que se ajusta ao modelo cinético de Michaelis e Menten (1913), e outro não saturável, de baixa afinidade, que predomina em altas concentrações externas de amônio (acima de $1 \mathrm{mM}$ ) caracterizado por uma dependência linear da concentração externa de amônio (ULLRICH et al., 1984; WANG et al., 1993; KRONZUCKER; SIDDIQI; GLASS, 1996). Esse tipo de transportador não saturável foi observado em fungos em concentração milimolar (SHELDEN et al., 2001).

O sistema de alta afinidade (High-Affinity Transport System - HATS) apresenta menores valores de $\mathrm{K}_{\mathrm{M}}$ (ULLRICH et al., 1984; WANG et al., 1993; KRONZUCKER; SIDDIQI; GLASS, 1996). Já o sistema denominado de baixa afinidade (Low-Affinity Transport System - LATS), não saturável, é responsável pelo transporte de nutrientes que se encontram em a altas concentrações externas, exibindo aumento linear de atividade em resposta à concentração de amônio (WANG et al., 1993; KRONZUCKER; SIDDIQI; GLASS, 1996; RAWAT et al., 1999). Este sistema é responsável pela manutenção de grande influxo em situações de alta disponibilidade externa do nutriente. O sistema HATS é altamente dependente do metabolismo, portanto, os desacopladores da membrana plasmática (de força próton-motriz) inibem a sua atividade (GLASS et al., 1997).

Wang et al. (1993), Kronzucker, Siddiqi e Glass (1996) usaram ${ }^{13} \mathrm{~N}$ para medir o influxo de $\mathrm{NH}_{4}^{+}$ em raízes de arroz. Inicialmente foi determinada a meia-vida $(1 / 2 \mathrm{~T})$ de transferência de $\mathrm{NH}_{4}^{+}$da parede celular ao citoplasma, e a partir daí foi possível determinar a velocidade de fluxo através da membrana plasmática. Desse modo, o fluxo de $\mathrm{NH}_{4}^{+}$para o citoplasma e para o vacúolo pôde 
ser caracterizado. Em arroz, com a diminuição do suprimento de $\mathrm{NH}_{4}^{+}$de $1 \mathrm{mM}$ para $2 \mu \mathrm{M}$, durante a pré-cultura, ocorreu, em ambos, um decréscimo nos valores de $\mathrm{K}_{\mathrm{M}}$ e um aumento nos valores de $\mathrm{V}_{\max }$. $\mathrm{O}$ valor de $\mathrm{V}_{\text {max }}$ para o influxo de $\mathrm{NH}_{4}^{+}$em arroz foi fortemente reduzido com uma exposição prévia a altos níveis de $\mathrm{NH}_{4}^{+}$(GLASS et al., 1997).

Ullrich et al. (1984) sugeriu que o LATS para $\mathrm{NH}_{4}^{+}$parece não causar despolarização de diferença de potencial trasmembrana $(\Delta \Psi)$, (como ocorre em HATS), uma observação que é compatível com a entrada de $\mathrm{NH}_{4}^{+}$. Esse sistema de baixa afinidade foi examinado por Wang et al. (1993) e por Kronzucker, Siddiqi e Glass (1996) em raízes de arroz. Em contrapartida aos estudos em Lemna, o fluxo de amônio por LATS em arroz despolariza fortemente $\Delta \Psi$, como ocorre com HATS, que é um fenômeno compatível com a entrada de um cátion mais do que a de $\mathrm{NH}_{3}$, que é eletricamente neutro (GLASS et al., 1997).

O influxo de $\mathrm{NH}_{4}^{+}$via HATS parece ser regulado pelo estado nutricional da planta em relação ao nitrogênio (LEE; RUDGE, 1986; WANG et al., 1993; KRONZUCKER et al., 1998; GAZZARRINI et al., 1999; RAWAT et al., 1999; HOWITT; UDVARDI, 2000). Em geral, condições de restrição de nitrogênio levam a um aumento da atividade de HATS, enquanto que, altas concentrações de amônio ou de produtos de sua assimilação como a glutamina levam a repressão da atividade de HATS que também pode ser regulada geneticamente (HOWITT; UDALL; VERMAAS, 1999).

As variedades selecionadas para este estudo apresentaram diferenças de eficiência no uso do nitrogênio (MACHADO, 1997). O objetivo deste trabalho foi avaliar parâmetros relativos à cinética de absorção do amônio e o desempenho metabólico de variedades de milho em ambientes com alta e baixa disponibilidade de nitrogênio.

\section{Material e métodos}

O experimento foi realizado no campus da UFRRJ, km 47, Seropédica, (RJ), e desenvolvido em câmara de germinação, casa de vegetação e laboratórios do Departamento de Solos do Instituto de Agronomia da UFRRJ, utilizando-se sementes de milho (Zea mays L.) de "variedades locais" (selecionadas por agricultores) e "variedades melhoradas" (produzidas por instituições de pesquisa ou comunidades agrícolas).

As variedades selecionadas foram: Catetão (Variedade Local) e as variedades melhoradas: BR 473 (CNPAB), BRS 4157 - Sol da Manhã e Eldorado (obtida por melhoramento através de enfoque participativo). As variedades melhoradas foram selecionadas em função de sua importância para a agricultura familiar da região sudeste do Brasil, onde foi realizada esta pesquisa.A seguir serão apresentadas algumas principais características das variedades de milho utilizadas no experimento: BRS 4157: Sol da Manhã NF (ou Nitroflint), com grãos tipo duros, alaranjados com segregação para branco, com predomínio das raças Cateto, Eto e Duros do Caribe, também com oito ciclos de seleção visando maior eficiência na utilização do $\mathrm{N}$ (SOARES et al., 1998); BR 473: Sintético de ciclo precoce, grãos amarelos, semiduros. Desenvolvida pelo intercruzamento de seis linhagens elites com qualidade protéica melhorada (QPM) (GUIMARÃES et al., 2004).

Nos últimos dois ciclos de seleção de progênies de meios irmãos foram selecionados para aumentar a adaptação ampla às condições do Sudeste e Sul do Brasil; Catetão: Variedade de ciclo normal e de porte alto, com endosperma de coloração laranja escuro e grãos do tipo duro. Ë uma variedade local obtida junto aos agricultores de Alegre-ES, Brasil (MACHADO et al., 2000); Eldorado: População de grãos dentados, amarelos, com segregação para branco com predomínio da raça Tuxpeño, com oito ciclos de seleção visando maior eficiência na utilização de N (MACHADO et al., 1992). 
As sementes de cada variedade foram colocadas para germinar em bandejas de plástico, contendo areia lavada e autoclavada. Após a semeadura as bandejas foram irrigadas mediante pulverização com spray de água destilada a cada doze horas, durante sete dias, período em que permaneceram em câmara com luz fluorescente intensa, simulando um fotoperíodo de 14 horas e temperatura ambiente $\left(25^{\circ} \mathrm{C}\right)$. Sete dias após a germinação (DAG), as plântulas foram selecionadas quanto a uniformidade e transplantadas para vasos plásticos com capacidade para 4 litros, contendo uma solução nutritiva, com pH 5,5 $\pm 0,1$ e 1/4 de sua força iônica (FERNANDES, 1983). Nesta situação, as plantas foram cultivadas em ambiente de casa de vegetação.

Para cada vaso foram transferidas seis plântulas, tendo como suporte tampas de isopor recobertas com papel alumínio. As plantas foram fixadas em cada orifício com auxilio de tiras de espuma sintética. Após quatro dias, a solução foi modificada para a metade da força iônica e depois de mais quatro dias, para força iônica total, definida para condução do experimento. Nesta última etapa procedeu-se ao desbaste, deixando-se apenas quatro plantas por vaso.

Durante todo o período de cultivo, os vasos foram aerados durante uma hora com intervalos de oito horas e a solução nutritiva renovada a cada dois dias. Entretanto, o pH foi corrigido diariamente.

Para o estudo da cinética de absorção de amônio, plantas inteiras de milho com 23 DAG foram transferidas para uma solução sem de nitrogênio, visando aumentar a capacidade de absorção das raízes, como recomendado por Lee e Rudge (1986).

Decorridas 60 horas de ausência de N, as plantas foram transferidas para vasos, com solução nutritiva, contendo $\mathrm{CaSO}_{4} 0,5 \mathrm{mM}$, para garantir a integridade das membranas celulares, em dois tratamentos com 1,43 e $8,57 \mathrm{mM}$ de $\mathrm{N}$ e pH 5,5, em que se utilizou o sulfato de amônio p.a. como fonte de nitrogênio.
Imediatamente após a transferência das plantas para a solução de estudo e a cada intervalo de 1,0 hora foram coletadas amostras de $10 \mathrm{~mL}$ da solução nutritiva (das $9,0 \mathrm{~h}$ às $17,0 \mathrm{~h}$ ). Outras duas coletas com intervalos de 24 e 48 horas, foram coletadas. As amostras foram analisadas com a finalidade de se obter as curvas de depleção do íon amônio.

Foi determinado também o $\mathrm{pH}$ das amostras de solução nutritiva coletadas em cada intervalo de tempo, para a caracterização do efluxo de prótons.

O estudo da cinética de absorção de amônio teve início quatro horas após o término do período escuro e os dados obtidos serviram de base para o cálculo dos parâmetros $\mathrm{V}_{\text {máx }}$ e $\mathrm{K}_{\mathrm{M}}$ de absorção de $\mathrm{N}_{-} \mathrm{NH}_{4}^{+}$utilizando metodologias semelhantes às descritas por Michaellis e Menten (1913) para cinética de enzimas. Empregou-se o processo gráfico-matemático proposto por Ruiz (1985) para calcular os valores de $\mathrm{V}_{\text {máx }} \mathrm{eK}_{\mathrm{M} \text {., }}$ baseado no programa “Cinética" (RUIZ; FERNANDES FILHO, 1992), de acordo com o método de Claassen e Barber (1974). O modelo de melhor ajuste foi utilizado para todas as concentrações.

As concentrações de amônio da solução nutritiva foram determinadas pelo método da destilação por arraste a vapor e posterior titulação com solução de $\mathrm{H}_{2} \mathrm{SO}_{4}$ (JONES JUNIOR, 1991) e as concentrações de $\mathrm{H}^{+}$em $\mathrm{H}_{3} \mathrm{O}^{+}$, foram calculadas levando-se em consideração que: $\mathrm{pH}=-\log \left[\mathrm{H}^{+}\right]$. Subtraindo-se das concentrações finais as iniciais, obteve-se o incremento de $\mathrm{H}^{+}$na solução (extrusão de prótons). Com estes dados foram determinados os parâmetros cinéticos $\mathrm{V}_{\text {max }}$ e $\mathrm{K}_{\mathrm{M}}$ em plantas de milho com 28 DAG.

Ao final do período de amostragem das soluções, as plantas foram colhidas e separadas em parte aérea e raíz. De cada planta foi retirado $1 \mathrm{~g}$ de matéria fresca, do terço médio tanto das folhas quanto das raízes. As amostras de folhas foram retiradas da terceira folha da base para o ápice. 
Cada amostra em separado foi colocada em etanol (80\%) macerada e por partição com adição de clorofórmio foi extraída a fase aquosa conforme Fernandes (1978), para análise da fração hidrossolúvel: N-amino (YEMM; COCKING, 1955), nitrato (CATALDO et al., 1975) e amônio (FELKER, 1977).

Da parte aérea e raízes foram obtidos as massas frescas e no caso das raízes foram também determinados os volumes. Após a determinação do volume radicular, as raízes de duas plantas de cada variedade foram mantidas em solução de etanol a $50 \%$ para determinação da área radicular.

Após a separação do material para análise da fração solúvel, a parte aérea e as raízes restantes foram secas em estufa de circulação forçada de ar, a $60{ }^{\circ} \mathrm{C}$ até peso constante, para a obtenção da massa de material seco. As amostras secas foram trituradas e submetidas à digestão sulfúrica e nitroperclórica, para se determinar os valores de N-total, $\mathrm{P}$ e $\mathrm{Mg}$ de acordo com as metodologias descritas em Tedesco (1982).

O delineamento experimental empregado foi o inteiramente casualizado, com 4 repetições, em esquema fatorial $2 \times 4$, em que os fatores foram dois níveis $\mathrm{N}^{-\mathrm{NH}_{4}+}(1,43$ e $8,57 \mathrm{mM})$ e 4 variedades de milho.

\section{Resultados e discussão}

A produção de massa fresca da parte aérea e das raízes, assim como a relação raiz/parte aérea e o volume radicular não foram influenciadas significativamente pelas doses de $\mathrm{N}$, exceto para a variedade Sol da Manhã, que teve uma redução da massa e volume de raízes com a maior dose de $\mathrm{N}$ (Tabela 1 e 2).

Tabela 1. Massa fresca da parte aérea e das raízes de variedades de milho sob diferentes doses de nitrogênio $(1,43$ e $8,57 \mathrm{mM}^{\mathrm{me} \mathrm{N}-\mathrm{NH}_{4}^{+}}$) aos $28 \mathrm{DAG}$.

\begin{tabular}{ccccc}
\hline & \multicolumn{2}{c}{$\begin{array}{c}\text { Parte aérea } \\
\text { (g/4plantas) }\end{array}$} & \multicolumn{2}{c}{$\begin{array}{c}\text { RAIZ } \\
\text { (g/4plantas) }\end{array}$} \\
\cline { 2 - 5 } Variedades & $1,43 \mathrm{mM}$ & $8,57 \mathrm{mM}$ & $1,43 \mathrm{mM}$ & $8,57 \mathrm{mM}$ \\
\hline Sol da Manhã & $85,51 \mathrm{aA}$ & $85,53 \mathrm{aA}$ & $64,14 \mathrm{aA}$ & $54,96 \mathrm{bB}$ \\
Catetão & $82,79 \mathrm{aA}$ & $84,41 \mathrm{aA}$ & $52,02 \mathrm{bA}$ & $47,34 \mathrm{bA}$ \\
Eldorado & $85,88 \mathrm{aA}$ & $87,34 \mathrm{aA}$ & $61,8 \mathrm{aA}$ & $64,15 \mathrm{aA}$ \\
BR473 & $87,15 \mathrm{aA}$ & $84,39 \mathrm{aA}$ & $58,58 \mathrm{abA}$ & $52,21 \mathrm{bA}$ \\
\hline C.V.\% & \multicolumn{3}{c}{8,77} \\
\hline
\end{tabular}

Médias seguidas da mesma letra minúscula nas colunas (variedades) e maiúscula nas linhas (tratamentos) não diferem entre si pelo teste de Tukey a 5\%.

Tabela 2. Relação raíz/parte aérea (\%) e volume radicular $\left(\mathrm{cm}^{3}\right)$ de variedades de milho sob diferentes doses de nitrogênio (solução 1,43 e $8,57 \mathrm{mM}_{\text {de }} \mathrm{N}^{-\mathrm{NH}_{4}^{+}}$) aos 28 DAG.

\begin{tabular}{|c|c|c|c|c|}
\hline \multirow{2}{*}{ Variedades } & \multicolumn{2}{|c|}{$\begin{array}{c}\text { Relação raíz/parte aérea } \\
(\%)\end{array}$} & \multicolumn{2}{|c|}{$\begin{array}{c}\text { Volume radicular } \\
\qquad\left(\mathrm{cm}^{3}\right)\end{array}$} \\
\hline & $1,43 \mathrm{mM}$ & $8,57 \mathrm{mM}$ & $1,43 \mathrm{mM}$ & $8,57 \mathrm{mM}$ \\
\hline Sol da Manhã & $75,08 \mathrm{aA}$ & $64,78 \mathrm{abA}$ & 34,12 a $\mathrm{A}$ & $26,62 \mathrm{bB}$ \\
\hline Catetão & $63,48 \mathrm{aA}$ & $56,51 \mathrm{bA}$ & $28,75 \mathrm{bA}$ & $26,60 \mathrm{bA}$ \\
\hline Eldorado & $72,00 \mathrm{aA}$ & $73,58 \mathrm{aA}$ & $31,62 \mathrm{aA}$ & $34,25 \mathrm{aA}$ \\
\hline BR473 & $67,75 \mathrm{aA}$ & $63,58 \mathrm{abA}$ & $26,62 \mathrm{bA}$ & $26,50 \mathrm{bA}$ \\
\hline C.V. \% & \multicolumn{2}{|c|}{11,64} & \multicolumn{2}{|c|}{7,99} \\
\hline
\end{tabular}

Médias seguidas da mesma letra minúscula nas colunas (variedades) e maiúscula nas linhas (tratamentos) não diferem entre si pelo teste de Tukey a $5 \%$. 
Sob o tratamento de 1,43 mM de $\mathrm{N}_{-} \mathrm{NH}_{4}^{+}$, as variedades Sol da Manhã e Eldorado apresentaram maior desenvolvimento radicular, diferindo apenas da variedade Catetão. Sob a dose de 8,57 mM, a variedade Eldorado apresentou maior desenvolvimento radicular que as demais variedades testadas (Tabela 1). É interessante observar que para este tratamento a variedade Eldorado apresentou também a maior relação raiz/parte aérea (Tabela 2).

O amônio absorvido é assimilado predominantemente no tecido radicular a expensa de esqueletos carbônicos de biomoléculas que podem ser originários do tecido radicular. Portanto, os resultados observados (Tabelas 1 e 2) podem indicar para a variedade Sol da Manhã, maior atividade metabólica na redução do amônio absorvido em relação às demais variedades.

Os valores dos parâmetros cinéticos de absorção

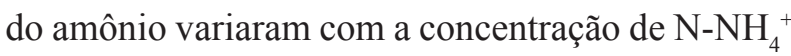
na solução (Figuras 1 e 2). Para todas as variedades, o maior $\mathrm{K}_{\mathrm{M}}$ foi observado no tratamento 8,57 $\mathrm{mM}$; entretanto, não foram verificadas diferenças significativas entre as variedades.

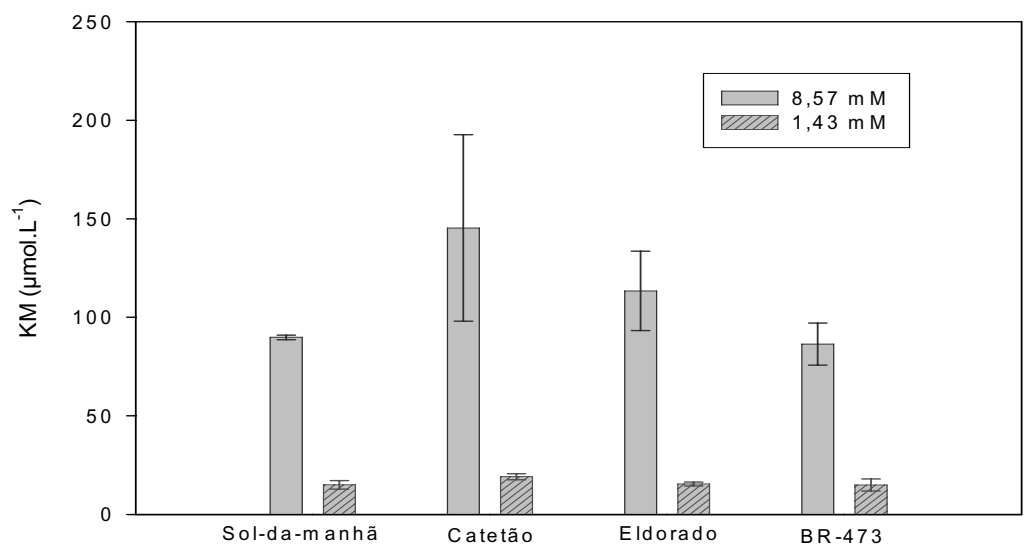

Figura 1. Constante de Michaelis - $\mathrm{K}_{\mathrm{M}}\left(\mu \mathrm{mol} \mathrm{L} \mathrm{L}^{-1}\right)$ de absorção de $\mathrm{NH}_{4}^{+}$de variedades de milho sob diferentes doses de nitrogênio em solução nutritiva $\left(1,43\right.$ e $\left.8,57 \mathrm{mM}^{\mathrm{M}} \mathrm{N}-\mathrm{NH}_{4}^{+}\right)$aos 28 DAG.

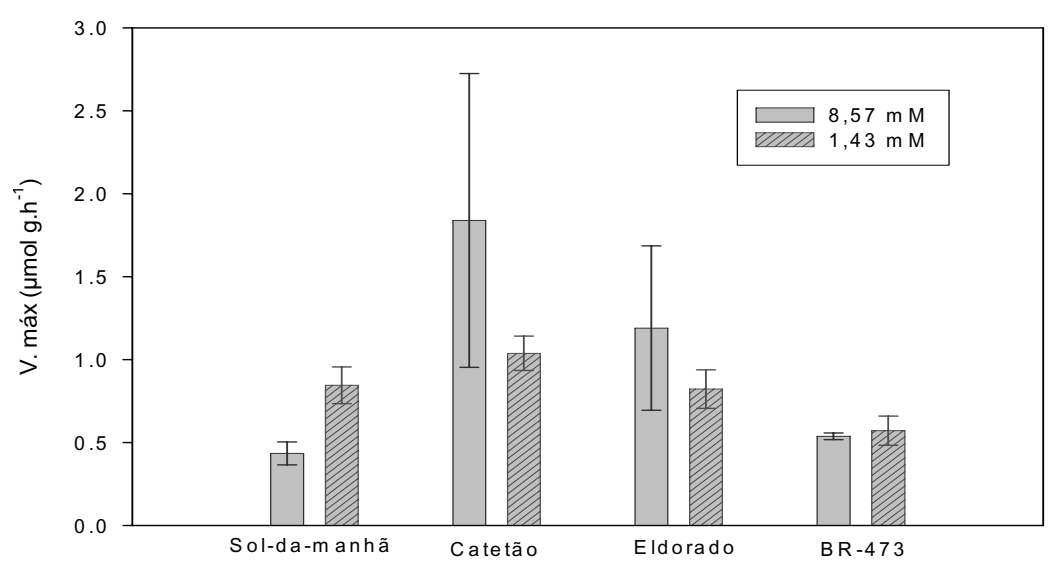

Figura 2. Velocidade Máxima (Vmax) de absorção de $\mathrm{NH}_{4}^{+}$de variedades de milho sob diferentes doses de nitrogênio em solução nutritiva $\left(1,43\right.$ e $8,57 \mathrm{mM}$ de $\left.\mathrm{N}^{-\mathrm{NH}_{4}}{ }^{+}\right)$aos 28 DAG. 
$\mathrm{O}$ valor de $\mathrm{V}_{\max }$ (Figura 2) variou com as variedades testadas independentemente da concetração considerada. Os maiores valores para $\mathrm{V}_{\max }$ foram obtidos com as variedades Catetão e Eldorado. O menor valor foi obtido com a BR 473. Somente para variedade Sol da Manhã a $V_{\max }$ diminuiu (aproximadamente 50\%) com o aumento do teor de N na solução.

Resultados semelhantes foram observados por Borges et al. (2002), avaliando os parâmetros cinéticos em variedades de milho (Catetão, BR 473, Eldorado e Sol da Manhã) em solução nutritiva de 20 e 120 mg N-NH4+/L. Os valores dos parâmetros cinéticos de absorção do amônio variaram com a concentração do nutriente na solução. A maior Vmax foi encontrada na variedade Catetão e a menor, na BR 473, não diferindo estatisticamente nas variedades Eldorado e Sol da Manhã. Entretanto no tratamento de 120 mgN-NH4 +/L, observou-se a diminuição da Vmáx na variedade Sol da Manhã . Este resultado também foi observado neste estudo, na maior dose de N, para a variedade Sol da Manhã.

Sistemas de transporte de alta e de baixa afinidade apresentam distintos valores de $\mathrm{K}_{\mathrm{M}}$ aparentes(WANG et al., 1993). Como o $K_{M}$ representa a concentração de substrato na qual o processo de transporte atinge a metade da velocidade máxima, a afinidade pelo substrato é o parâmetro mais relevante na descrição dos sistemas de transporte iônico envolvendo o processo de absorção de nutrientes pelas plantas. Um transportador de alta afinidade seria aquele capaz de transportar nutrientes quando em baixas concentrações externas. Baixa afinidade, muitas vezes está correlacionada com uma alta capacidade de transporte, que é um parâmetro crucial para manutenção de um grande influxo em elevadas concentrações externas. Assim, a distinção entre sistemas de alta afinidade/baixa capacidade e baixa afinidade/alta capacidade de transporte de $\mathrm{NH}_{4}^{+}$, reflete seus papéis fisiológicos com maior precisão do que a baseada apenas na afinidade (WIRÉN et al., 2000).
Os valores de $\mathrm{K}_{\mathrm{M}}$ determinados para as variedades testadas (Figura 1) indicam que na dose de 1,43 mM predomina um sistema de alta afinidade (HATS) enquanto que, na de 8,57 mM predomina o sistema de transporte de baixa afinidade (LATS). $\mathrm{Na}$ menor dose de $\mathrm{N}-\mathrm{NH}_{4}^{+}$, verifica-se os menores valores de $\mathrm{Km}$ e, na maior dose, os maiores valores de Km. Resultados semelhantes foram encontrados por Borges et al., (2002).

Para a variedade Sol da Manhã, o aumento do suprimento externo de $\mathrm{NH}_{4}^{+}$, resultou em aumento do $\mathrm{K}_{\mathrm{M}}$ e diminuição da $\mathrm{V}_{\max }$ (influxo máximo), comportamento que diferiu das demais variedades. Resultados semelhantes aos da variedade Sol da Manhã foram observados na cultura do arroz, em que o aumento de $\mathrm{N}-\mathrm{NH}_{4}^{+}$, resultou em aumento do valor de $\mathrm{K}_{\mathrm{M}}$ e diminuição da $\mathrm{V}_{\text {max }}$ (WANG et al., 1993; WIRÉN et al., 2000).

O comportamento da variedade Sol da Manhã indica uma adaptação do sistema de absorção a menor disponibilidade de $\mathrm{N}_{-} \mathrm{NH}_{4}^{+}$na solução externa, conferindo a esta variedade maior eficiência na absorção de $\mathrm{NH}_{4}^{+}$, como indicado por Wirén et al. (2000).

Mais do que o $\mathrm{K}_{\mathrm{M}}$, a $\mathrm{V}_{\text {max }}$ traduz a eficiência do sistema na absorção de $\mathrm{N}$, porque indica a absorção real de $\mathrm{N}$ e não apenas a tendência. Assim, avaliando os valores de $\mathrm{V}_{\text {max }}$ obtidos com a solução de baixa disponibilidade de $\mathrm{N}$, pode-se inferir que a variedade Catetão foi mais eficiente na absorção de $\mathrm{N}_{-} \mathrm{NH}_{4}^{+}$, enquanto a BR 473 apresentou a menor eficiência.

Enquanto as variedades Catetão, Eldorado e BR 473 apresentarama predominânciadetransportadores de $\mathrm{N}_{-} \mathrm{NH}_{4}^{+}$de baixa afinidade e alta capacidade de transporte, a Sol da Manhã apresentou sistemas de baixa afinidade e de baixa capacidade de transporte de $\mathrm{N}-\mathrm{NH}_{4}^{+}$, contrariando as expectativas.

Os dados apresentados na (Figura 3) confirmam a hipótese de que o sistema de alta afinidade para transporte de $\mathrm{NH}_{4}^{+}$presente nas membranas 
celulares do sistema radicular está associado a mecanismos de extrusão de prótons quando em baixa concentração externa de $\mathrm{N}-\mathrm{NH}_{4}{ }^{+}$. Para o caso

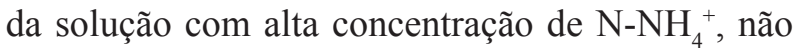
foi observada correlação entre a concentração e o tempo de exposição das raízes.

Sob a menor dose de nitrogênio, os valores de extrusão de prótons apresentaram uma correlação negativa com a concentração do íon $\mathrm{NH}_{4}^{+}$na solução nutritiva (Figura 4), confirmando a hipótese de que a assimilação de $\mathrm{NH}_{4}^{+}$é acompanhada por uma produção aproximadamente equimolar de $\mathrm{H}^{+}$, da atividade da $\mathrm{H}^{+}$-ATPase da membrana citoplasmática, e uma conseqüente extrusão de $\mathrm{H}^{+}$ para a solução externa, como indicado por Wirén et al. (2000) e Taylor e Bloom (1998).

A correlação negativa entre concentração de amônio na solução nutritiva e extrusão de $\mathrm{H}^{+}$ pelas plantas (Figura 4), indica que as variedades
Catetão e a Sol da Manhã foram mais eficientes na absorção de $\mathrm{N}_{-} \mathrm{NH}_{4}^{+}$, uma vez apresentaram maiores valores para o coeficiente angular das retas correspondentes a estas variedades. Estes dados indicam que para a mesma quantidade de amônio assimilado pelas plantas, menores quantidades de prótons são extrudidas por Catetão e Sol da Manhã. Por outro lado, indica também que a atividade da enzima $\mathrm{H}^{+}$-ATPase é menor para estas variedades, ou seja, há maior eficiência energética no processo de absorção/assimilação do $\mathrm{N}-\mathrm{NH}_{4}^{+}$.

Não foram observadas diferenças entre os teores foliares de $\mathrm{N}$ entre as variedades para os dois níveis de $\mathrm{N}_{-} \mathrm{NH}_{4}^{+}$, o que pode ser indicativo de que as mesmas possuem mecanismos igualmente eficientes de ajuste na absorção de amônio (Figura 5). Estes resultados são corroborados pelos encontrados por Borges et al. (2002), pois os autores avaliaram estas mesmas variedades e também não encontraram diferenças para os teores de $\mathrm{N}$ nas folhas e raízes.

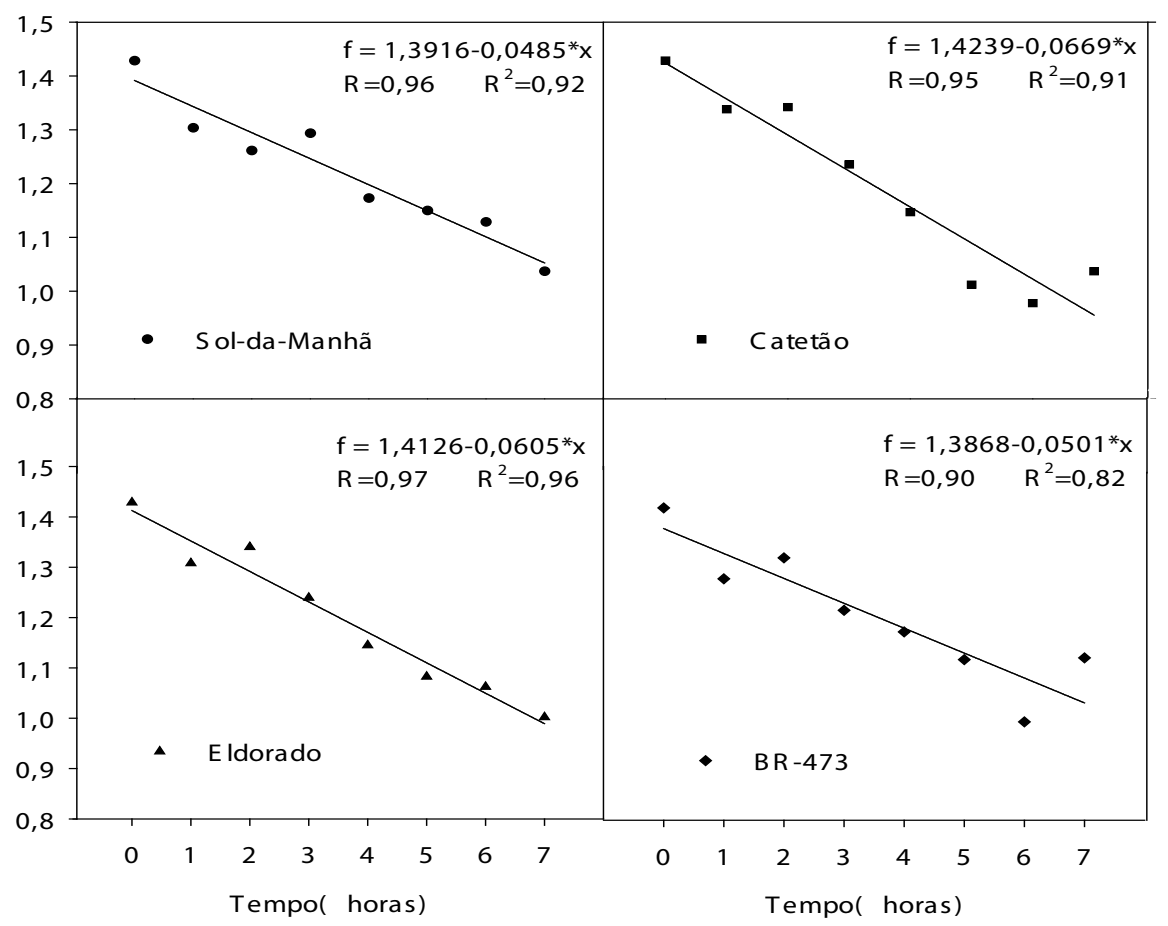

Figura 3. Variações na concentração de $\mathrm{N}_{-} \mathrm{NH}_{4}^{+}$da solução nutritiva $\left(1,43 \mathrm{mM}\right.$ de $\left.\mathrm{N}_{-} \mathrm{NH}_{4}^{+}\right)$para diferentes variedades de milho em função do tempo de imersão das raizes. 


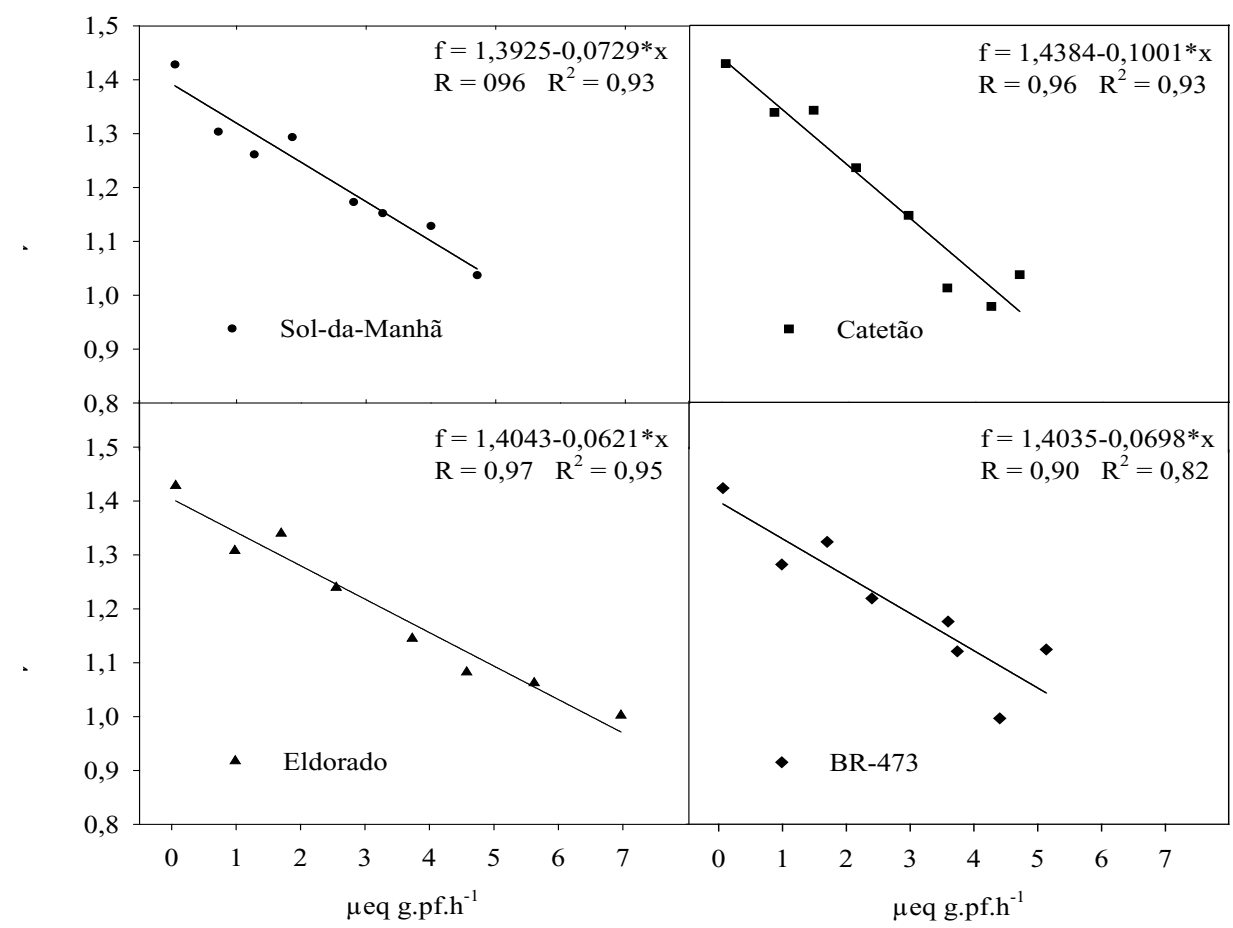

Figura 4. Correlação entre extrusão de $\mathrm{H}^{+}$e concentração de $\mathrm{NH}_{4}^{+}$na solução nutritiva de quatro variedades de milho sob a dose de nitrogênio de $1,43 \mathrm{mM}$ de $\mathrm{N}-\mathrm{NH}_{4}^{+}$.

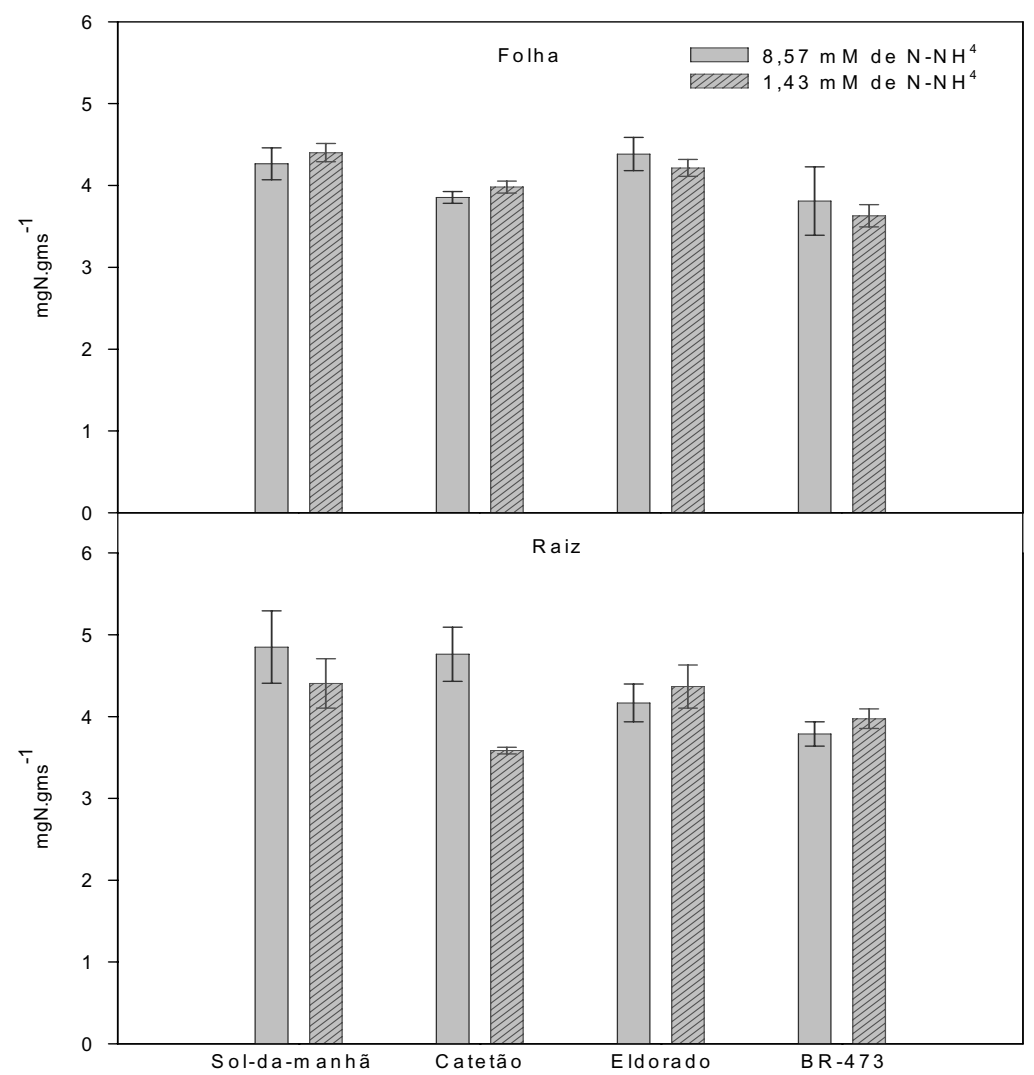

Figura 5. Teor de $\mathrm{N}$-total $\left(\mathrm{mg} \mathrm{N}^{-}\right.$-total $\left.\mathrm{gmf}^{-1}\right)$ na parte aérea e nas raízes de quatro variedades de milho, sob diferentes doses de nitrogênio $\left(1,43\right.$ e 8,57 $\left.\mathrm{mM}_{\text {de }} \mathrm{N}-\mathrm{NH}_{4}^{+}\right)$aos 28 DAG. 
Em relação aos teores de $\mathrm{N}$-amino na parte aérea e raiz, não foram observadas diferenças estatísticas para os tratamentos com $\mathrm{N}$ entre todas as variedades testadas. Entre as doses de N, observaram-se diferenças apenas na menor dose, sendo que a variedade Eldorado apresentou o menor teor de $\mathrm{N}$-amino na parte aérea e a BR473 nas raízes (Tabela
3). O acúmulo de aminoácidos e amidas é uma característica de plantas sob condições de toxidade por amônio.

De maneira geral, observou-se uma tendência de maiores teores de $\mathrm{N}$-amino nas raízes, independente da dose e variedade (Tabela 3 ). Tal fato sugere que a assimilação de $\mathrm{N}_{-} \mathrm{NH}_{4}^{+}$ocorre principalmente nesse órgão.

Tabela 3. Teor de $\mathrm{N}$-amino ( $\mu$ moles $\mathrm{N}$-amino.gmf ${ }^{-1}$ ) na parte aérea e raízes de quatro variedades de milho, sob diferentes doses de nitrogênio $\left(1,43\right.$ e $\left.8,57 \mathrm{mM}_{\text {de }} \mathrm{N}-\mathrm{NH}_{4}^{+}\right)$aos 28 DAG.

\begin{tabular}{|c|c|c|c|c|}
\hline \multirow[t]{2}{*}{ Variedades } & \multicolumn{2}{|c|}{$\begin{array}{c}\text { Parte aérea } \\
\mu \text { moles N-amino/gmf }\end{array}$} & \multicolumn{2}{|c|}{$\begin{array}{c}\text { RAIZ } \\
\mu \text { moles N-amino/gmf }\end{array}$} \\
\hline & $1,43 \mathrm{mM}$ & $8,57 \mathrm{mM}$ & $1,43 \mathrm{mM}$ & $8,57 \mathrm{mM}$ \\
\hline Sol da Manhã & $4,89 \mathrm{aA}$ & $8,54 \mathrm{aA}$ & $7,50 \mathrm{aA}$ & $10,75 \mathrm{aA}$ \\
\hline Catetão & $4,97 \mathrm{aA}$ & $4,77 \mathrm{aA}$ & $8,00 \mathrm{aA}$ & 7,96aA \\
\hline Eldorado & $1,25 \mathrm{aB}$ & $5,15 \mathrm{aA}$ & $4,17 \mathrm{aA}$ & $10,78 \mathrm{aA}$ \\
\hline BR473 & $1,40 \mathrm{aA}$ & $4,07 \mathrm{aA}$ & 7,54aB & $11,62 \mathrm{aA}$ \\
\hline C.V \% & \multicolumn{2}{|c|}{29,06} & \multicolumn{2}{|c|}{56,74} \\
\hline
\end{tabular}

Médias seguidas da mesma letra minúscula na coluna (variedades) e mesma letra maiúscula na linha (tratamentos) não diferem estatisticamente pelo teste de Tukey a 5\%.

No tratamento com a maior concentração de amônio, a variedade Sol da Manhã apresentou teores de N-Amino mais elevados na parte aérea e a BR 473 teve este comportamento nas raízes. Entretanto, não foram constatadas diferenças significativas entre as demais variedades.

Quando a fonte de nitrogênio é $\mathrm{N}^{-\mathrm{NH}_{4}}{ }^{+}$, as plantas necessitam de esqueletos carbônicos para a assimilação/absorção do amônio, sintetizando aminoácidos e amidas. Inicialmente, a fonte desses esqueletos carbônicos seria carbonos prontamente assimiláveis como os açúcares solúveis, que são deslocados da parte aérea para as raízes, local dessa síntese. Em uma segunda etapa, com o prosseguimento do influxo de $\mathrm{NH}_{4}^{+}$deve ocorrer uma mobilização de carboidratos não solúveis da própria raiz, reduzindo assim a sua matéria fresca, como se observou neste experimento na variedade
Sol da Manhã, que apresentou redução da massa fresca de raízes no tratamento com a maior dose de $\mathrm{N}-\mathrm{NH}_{4}^{+}$(Tabela 1).

Entre as variedades testadas, a Eldorado apresentou menor teor de $\mathrm{NO}_{3}^{-}$na parte aérea e nas raízes nos tratamentos de 1,43 e $8,57 \mathrm{mM}$ de $\mathrm{N}^{-\mathrm{NH}_{4}^{+}}$, respectivamente (Tabela 4). Os maiores teores de $\mathrm{NO}_{3}^{-}$na parte aérea observados para as variedades Sol da Manhã, BR 473 e Catetão indica a maior eficiência das mesmas na utilização do nitrogênio absorvido da solução nutritiva na fase de desenvolvimento vegetativo (HIREL et al., 2001) quando comparado à variedade Eldorado. Segundo Fernandes et al. (2005), geralmente, o aproveitamento de $\mathrm{N}$ decresce com o aumento das doses aplicadas, uma vez que o suprimento deste nutriente excede as necessidades da cultura. 
Tabela 4. Teor de $\mathrm{NO}_{3}^{-}\left(\mathrm{mg} \mathrm{NO}_{3}^{-} \cdot \mathrm{gmf}^{-1}\right)$ - na parte aérea e raízes de quatro variedades de milho, sob diferentes doses de nitrogênio $\left(1,43\right.$ e $8,57 \mathrm{mM}$ de $\mathrm{N}-\mathrm{NH}_{4}^{+}$.

\begin{tabular}{|c|c|c|c|c|}
\hline \multirow[t]{2}{*}{ Variedades } & \multicolumn{2}{|c|}{$\begin{array}{c}\text { Parte aérea } \\
\text { mg NO}_{3}^{-} \cdot \text { gmf }^{-1}\end{array}$} & \multicolumn{2}{|c|}{$\begin{array}{c}\text { RAIZ } \\
\text { mg NO}_{3}^{-} \cdot \text { gmf }^{-1} \\
\end{array}$} \\
\hline & $1,43 \mathrm{mM}$ & $8,57 \mathrm{mM}$ & $1,43 \mathrm{mM}$ & $8,57 \mathrm{mM}$ \\
\hline Sol da Manhã & $0,76 \mathrm{aA}$ & $0,58 \mathrm{aA}$ & $2,00 \mathrm{aA}$ & $2,26 \mathrm{aA}$ \\
\hline Catetão & $0,62 \mathrm{aA}$ & $0,69 \mathrm{aA}$ & $2,18 \mathrm{aA}$ & $2,08 \mathrm{aA}$ \\
\hline Eldorado & $0,16 \mathrm{bB}$ & $0,36 \mathrm{aA}$ & $0,74 \mathrm{aA}$ & $1,27 \mathrm{bA}$ \\
\hline BR473 & $0,67 \mathrm{aA}$ & $0,6 \mathrm{aA}$ & $7,25 \mathrm{aA}$ & $1,82 \mathrm{abA}$ \\
\hline C.V. \% & \multicolumn{2}{|c|}{7,19} & \multicolumn{2}{|c|}{7,02} \\
\hline
\end{tabular}

Médias seguidas da mesma letra minúscula na coluna (variedades) e mesma letra maiúscula na linha (tratamentos) não diferem estatisticamente pelo teste de Tukey a $5 \%$.

As variedades Eldorado e BR 473 apresentaram uma variação significativa no teor de fósforo na massa seca da parte aérea entre os dois tratamentos, com maior teor na menor dose de $\mathrm{N}$, em que predomina o sistema HATS de transporte de $\mathrm{NH}_{4}^{+}$ e que está associado à extrusão de $\mathrm{H}^{+}$. A diminuição do $\mathrm{pH}$ da rizosfera pode afetar a absorção do fósforo por dois motivos: alteração da razão entre as formas de fosfato absorvidas pela planta $\left(\mathrm{H}_{2} \mathrm{PO}_{4}^{-} / \mathrm{HPO}_{4}^{--}\right) \mathrm{e}$ aumento da concentração de $\mathrm{H}^{+}$para co-transporte. Estas variedades apresentaram, após 7 horas de exposição a doses de $\mathrm{N}-\mathrm{NH}_{4}^{+}$, os maiores valores de extrusão de prótons (menor coeficiente angular da reta de correlação) (Figura 5). Tais variedades provavelmente apresentam melhor adaptação do que as demais para absorção do fósforo em circunstâncias de baixa disponibilidade de $\mathrm{N}_{-} \mathrm{NH}_{4}^{+}$.

A maior concentração de fósforo, nas duas variedades observada no tratamento com 1,43 $\mathrm{mM}$, pode ser atribuída à maior concentração do
ATP necessário à atividade da enzima $\mathrm{H}^{+}$-ATPase da membrana plasmática do tecido radicular. O decréscimo de ATP pode ser responsável por restrição na síntese do sistema de transporte de $\mathrm{N}$, ou a limitação de ATP pode restringir a energia disponível diretamente para o transporte de nitrato contra o gradiente de potencial eletroquímico (RUFTY JUNIOR et al., 1993).

A maior ou menor disponibilidade de $\mathrm{N}$ pode exercer efeito na assimilação de $\mathrm{P}$ e interações sinergísticas entre esses nutrientes já foram identificadas na cultura do milho (MACHADO et al. 2004; REIS JUNIOR et al., 2008). Avaliando a localização de fósforo e de nitrogênio afetando os parâmetros cinéticos de absorção de nitrogênio em milho (Híbrido BR 201) em casa de vegetação, Alves et al. (1998) observaram que no tratamento sem adição de $\mathrm{P}$ e com 3,71 ou 7,42 mmoles $\mathrm{L}^{-1}$ $\mathrm{N}^{-\mathrm{NH}_{4}^{+}}$, na parte aérea e na raíz, a concentração de $\mathrm{P}$ foi em média 0,41 e $0,34 \%$, respectivamente.

Tabela 5. Teor de $\mathrm{P}(\% \mathrm{Pm} / \mathrm{m})$ - na parte aérea e raízes de quatro variedades de milho, sob diferentes doses de nitrogênio $\left(1,43\right.$ e $8,57 \mathrm{mM}$ de $\mathrm{N}_{-} \mathrm{NH}_{4}^{+}$aos 28 DAG.

\begin{tabular}{ccccc}
\hline \multirow{2}{*}{ Variedades } & \multicolumn{2}{c}{$\begin{array}{c}\text { Parte aérea } \\
\text { \%P (m/m) }\end{array}$} & \multicolumn{2}{c}{$\mathbf{R A I Z}$} \\
& $\mathbf{1 , 4 3} \mathbf{~ m M}$ & $\mathbf{8 , 5 7} \mathbf{~ m M}$ & $\mathbf{1 , 4 3} \mathbf{~ m M}$ & $\mathbf{8 , 5 7} \mathbf{~ m M}$ \\
\cline { 2 - 5 } & $0,51 \mathrm{aA}$ & $0,88 \mathrm{aA}$ & $0,74 \mathrm{aA}$ & $0,88 \mathrm{aA}$ \\
Sol da Manhã & $0,54 \mathrm{aA}$ & $0,45 \mathrm{abA}$ & $0,55 \mathrm{aA}$ & $0,33 \mathrm{aA}$ \\
Catetão & $0,74 \mathrm{aA}$ & $0,24 \mathrm{~b} \mathrm{~B}$ & $0,84 \mathrm{aA}$ & $0,40 \mathrm{aA}$ \\
Eldorado & $0,87 \mathrm{aA}$ & $0,22 \mathrm{~b} \mathrm{~B}$ & $0,66 \mathrm{aA}$ & $0,98 \mathrm{aA}$ \\
BR473 & \multicolumn{3}{c}{16,73} \\
\hline
\end{tabular}

Médias seguidas da mesma letra minúscula na coluna (variedades) e mesma letra maiúscula na linha (tratamentos) não diferem estatisticamente pelo teste de Tukey a 5\%. 
A variedade Eldorado apresentou na parte aérea, menor teor de $\mathrm{Mg}$ com a dose de 1,43 $\mathrm{mM}$ do que com a de $8,57 \mathrm{mM}$ de $\mathrm{N}_{-} \mathrm{NH}_{4}^{+}$. Nas raízes, esta variedade apresentou o maior teor de $\mathrm{Mg}$ sob a menor dose de $\mathrm{N}$ do que as demais variedades. Este resultado pode estar associado à maior utilização de ATP como substrato da enzima $\mathrm{H}^{+}$-ATPase no tecido radicular para a extrusão de prótons, que nesta variedade apresentou valor superior ao das demais (Tabela 6).

Avaliando os teores de $\mathrm{Mg}$ na parte aérea da variedade Sol da Manhã e do Híbrido BRS 1010, Oliveira (2006) verificou teores de 0,099 e 0,095, respectivamente. $\mathrm{O}$ autor utilizou como corretivo de solo $\mathrm{CaCO}_{3}$ e adubação com $\mathrm{N}\left(\mathrm{KNO}_{3}\right)$ equivalente à dose de $40 \mathrm{~kg} \mathrm{ha}^{-1}$.

Tabela 6. Teor de $\mathrm{Mg}(\% \mathrm{Mg} \mathrm{m} / \mathrm{m})$ - na parte aérea e raízes de quatro variedades de milho, sob diferentes doses de nitrogênio $\left(1,43\right.$ e $8,57 \mathrm{mM}$ de $\mathrm{N}-\mathrm{NH}_{4}{ }^{+}$aos 28 DAG.

\begin{tabular}{ccccc}
\hline \multirow{2}{*}{ Variedades } & \multicolumn{2}{c}{$\begin{array}{c}\text { Parte aérea } \\
\text { \%Mg (m/m) }\end{array}$} & \multicolumn{2}{c}{$\begin{array}{c}\text { RAIZ } \\
\text { \%g (m/m) }\end{array}$} \\
\cline { 2 - 5 } & $\mathbf{1 , 4 3} \mathbf{~ m M}$ & $\mathbf{8 , 5 7} \mathbf{~ m M}$ & $\mathbf{1 , 4 3} \mathbf{~ m M}$ & $\mathbf{8 , 5 7} \mathbf{~ m M}$ \\
\hline Sol da Manhã & $0,016 \mathrm{aA}$ & $0,018 \mathrm{aA}$ & $0,009 \mathrm{aA}$ & $0,011 \mathrm{aA}$ \\
Catetão & $0,019 \mathrm{aA}$ & $0,032 \mathrm{aA}$ & $0,006 \mathrm{aA}$ & $0,008 \mathrm{aA}$ \\
Eldorado & $0,021 \mathrm{aB}$ & $0,046 \mathrm{aA}$ & $0,024 \mathrm{aA}$ & $0,014 \mathrm{aA}$ \\
BR473 & $0,027 \mathrm{aA}$ & $0,187 \mathrm{aA}$ & $0,008 \mathrm{aA}$ & $0,009 \mathrm{aA}$ \\
\hline C.V\% & \multicolumn{3}{c}{32,66} \\
\hline
\end{tabular}

Médias seguidas da mesma letra minúscula na mesma coluna e letra maiúscula igual na mesma linha não diferem significativamente pelo teste de Tukey a $5 \%$.

\section{Conclusões}

$\mathrm{Na}$ avaliação dos parâmetros cinéticos (Vmax e Km) para absorção do $\mathrm{NH}_{4}^{+}$entre as variedades estudadas, a variedade Sol da Manhã apresentou maior desenvolvimento de sistemas de absorção de $\mathrm{N}_{-} \mathrm{NH}_{4}^{+}$de alta afinidade, enquanto que nas variedades Catetão e Eldorado o maior desenvolvimento foi de sistemas de baixa afinidade e alta capacidade.

A variedade Sol da Manhã foi mais eficiente na absorção de amônio à resposta às condições de menor disponibilidade de $\mathrm{N}$ na solução externa. Essa variedade apresentou redução na massa fresca das raízes sob a maior dose de $\mathrm{N}-\mathrm{NH}_{4}^{+}$provavelmente pela predominância do sistema HATS e por sua menor eficiência na resposta à indução de LATS para $\mathrm{NH}_{4}^{+}$.

As variedades Catetão e Sol da Manhã apresentaram menor extrusão de prótons sob condições de baixa disponibilidade de $\mathrm{N}^{-\mathrm{NH}_{4}^{+}}$, tornando o processo de absorção energeticamente mais econômico.

Os maiores teores de nitrato $\left(\mathrm{NO}_{3}^{-}\right)$na matéria fresca da parte aérea das variedades Sol da Manhã, BR 473 e Catetão podem indicar potencial de maior eficiência na absorção e utilização do nitrogênio.

\section{Referências bibliográficas}

ALVES, V. M. C.; MAGALHÃES, J. V.; NOVAIS, R. F.; BAHIA FILHO, A. F. C.; OLIVEIRA, C. A.; FRANÇA, C. C. M. Localização de fósforo e de nitrogênio afetando os parâmetros cinéticos de absorção de nitrogênio em milho. Revista Brasileira de Fisiologia Vegetal, Londrina, v. 10, n. 3, p. 197-201, 1998.

BECHING, J. H. On the mechanism of ammonium uptake by maize roots. Acta Botânica Neerlandica, Amsterdam, v. 5, p. 2-79, 1956.

BORGES, E. A.; PINHO, L. G. R.; ANDRADE, A. C.; QUEROZ, L. H.; SANTOS, T. J.; SOUZA, S. R.; FERNANDES, M. S. Cinética de absorção de nitrogênio em genótipos de milho. In: REUNIÃO BRASILEIRA 
DE BIOLOGIA DO SOLO, 4., 2002, Rio de Janeiro. FertiBio 2002. Rio de Janeiro: UFRRJ, 2002. CD-ROM.

CATALDO, D. A.; HAROON, M.; SCHRADER, L. E.; YOUNGS, V. L. Rapid colorimetric determination of nitrate in plant tissue by nitration of salicylic acid. Communications in Soil Science and Plant Analysis, New York, v. 6, n. 1, p.71-80, 1975.

CLAASSEN, N.; BARBER, S. A. A method for characterizing the relation between nutrient concentration and flux into root of intact plants. Plant Physiology, Bethesda, v. 54, n. 4, p. 564-568, 1974.

EPSTEIN, E.; HAGEN, C. E. A kinetic study of the absorption of alkali cations by barley roots. Plant Physiology, Bethesda, v. 27, n. 3, p. 457-472, 1952.

FELKER, P. Microdetermination of nitrogen in seed protein extratcs. Analytical Chemistry, Washington, v.49, n. 7, p.1080, 1977.

FERNANDES, F. C.S.; BUZETTI, S.; ARF, O.; ANDRADE, J. A. C. Doses, eficiência e uso de nitrogênio por seis cultivares de milho. Revista Brasileira de. Milho e Sorgo, Sete Lagoas, v. 4, n. 2, p.195-204, 2005.

FERNANDES, M. S. Absorção e metabolismo de nitrogênio em plantas. Rio de Janeiro: UFRRJ, 1978. (Boletim técnico, n. 1)

FERNANDES, M. S. Light and temperature influences on the free amino acid pool composition of rice plants. Actividades en Turrialba, Turrialba, v. 33, n. 3, p. 297-301, 1983.

GAZZARRINI, S.; LEJAY, L.; GOJON, A.; NINNEMANN, O.; FROMMER, W. B.; WIRÉN, N. Three functional transporters of constitutive, diurnally regulated and starvation-induced uptake of ammonium into arabidopsis roots. Plant Cell Physiology, Oxford, v. 11, n. 5, p. 937-948, 1999.

GLASS, A. D.; ERNER Y.; KRONZUCKER H. J.; SCHJOERRING J. K.; SIDDIQI, M.Y.; WANG, M. Y. Ammonium fluxes into plant roots: energetics, kinetics and regulation. Journal of Plant Nutrition and Soil Science, Oxford, v. 160, n. 2, p.261-268, 1997.

GUIMARÃES, P. E. O.; PACHECO, C. A. P.; PAES, M. C. D.; SANTOS, M. X.; PARENTONI, S. N.; GAMA, E. E. G.; MEIRELLES, W. F.; RIBEIRO, P. H. E.; MONTEIRO, M. A. R. BR 473: variedade de milho amarela com qualidade protéica melhorada (QPM). Sete Lagoas: EMBRAPA, 2004. (Comunicado Técnico, n. 105)
HIREL, B.; BERTIN, P.; QUILLERÉ, I.; BOURDONCLE, W.; ATTAGNANT, C.; DELLAY, C.; GOUY, A.; CADIOU, S.; RETAILLIAU, C.; FALQUE, M.; GALLAIS, A. Towards a better understanding of the genetic and physiological basis for nitrogen use efficiency in maize. Plant Physiology, Bethesda, v.125, n. 3, p.1258-1270, 2001.

HOWITT, C. A.; UDALL, P. K.; VERMAAS, W. F. J. Type $2 \mathrm{NADH}$ dehydrogenases in the cyanobacterium Synechocystis sp. strain PCC 6803 are involved in regulation rather than respiration. Journal of Bacteriology, Washington, v.181, n. 13, p. 3994-4003, 1999.

HOWITT, S. M.; UDVARDI, M. K. Structure, function and ammonium transporters in Plants. Biochimica et Biophysica Acta, Amsterdam, v.1465, n. 1/2, p. 152-170, 2000.

JONES JUNIOR, J. B. Kjeldahl method for nitrogen (N) determination. Madison: Micro-Macro, 1991.

KRONZUCKER H. J.; SCHJOERRING, J. K.; ERNER, Y.; KIRK, G. J. D.; SIDDIQI, M. Y.; GLASS, A. D. M. Dynamic interactions between root $\mathrm{NH}_{4}^{+}$influx and longdistance $\mathrm{N}$ translocation in rice: Insights into feedback processes. Plant Cell Physiology, Oxford, v. 39, n. 12, p.1287-1293, 1998.

KRONZUCKER, H. J.; SIDDIQI, M.Y.; GLASS, A. D. M. Kinetics of $\mathrm{NH}_{4}^{+}$influx in spruce. Plant Physiology, Bethesda, v.110, n. 3, p. 773-779, 1996.

LEE, R. B.; RUDGE, R. A. Effects of nitrogen defficiency on the absortion of nitrate and ammonium by barley plants. Annals of Botany, Oxford, v. 57, n. 4, p. 471-486, 1986.

MACHADO, A. T. Perspectiva do melhoramento genético em milho (Zea mays L.) visando eficiência na utilização do nitrogênio. $216 \mathrm{f}$. Tese (Doutorado em Ciência Genética) - Universidade Federal do Rio de Janeiro, Rio de Janeiro, 1997.

MACHADO,A.T.;MAGALHÃES,J.R.;MAGNAVACA, R.; SILVA, M. R. Determinação da atividade de enzimas envolvidas no metabolismo do nitrogênio em diferentes genótipos de milho. Revista Brasileira de Fisiologia Vegetal, Viçosa, v. 4, n. 2, p. 45-47, 1992.

MACHADO, C. T. Caracterização de genótipos de milho quanto a parâmetros morfológicos, fisiológicos e microbiológicos associados à eficiência de absorção e uso de fósforo. 2000. 365f. Tese (Doutorado em AgronomiaCiência do Solo) - Universidade Federal Rural do Rio de Janeiro, Seropédica, 2000. 
MACHADO, A. T.; MACHADO, C. T. T.; COELHO, C. H. M.; ARCANJO, J. N. Manejo da Diversidade Genética de Milho e Melhoramento Participativo em Comunidades Agrícolas nos Estados do Rio de Janeiro e do Espírito Santo. Planaltina: Embrapa Cerrados, 2002 (Boletim de Pesquisa e Desenvolvimento).

MACHADO, C.T.T.; MACHADO, A.T.; REIS JR, F.B.; VILELA, A.L. Acumulação de nitrogênio, fósforo e zinco e índices de eficiência de utilização e translocação de nutrientes em milho submetido a dois níveis de adubação nitrogenada. In: Reunião brasileira de fertilidade do solo e nutrição de plantas, 26; Reunião brasileira sobre micorrizas, 10; Simpósio brasileiro de microbiologia do solo, 7; Reunião brasileira de biologia do solo: avaliação das conquistas: base para estratégias futuras, 5, Lages, 2004. Viçosa, MG, SBCS/UDESC, 2004. CD-ROM.

MICHAELIS, L.; MENTEN, M. Die kinetik der invertinwirkung. Biochemische Zeitschrift, Berlin, York, v. 49, p. 333-369, 1913.

OLIVEIRA, S. A. R. Aplicação foliar de nitrato e de microorganismos eficazes (EM) e seus efeitos sobre a partição de nutrientes em variedades de milho (Zea mays L.) cultivadas com resíduo industrial. 2006. Dissertação (Mestrado em Agronomia) - Universidade Federal Rural do Rio de Janeiro, Seropédica.

RAWAT, S. R.; SILIM, S .N.; KRONZUCKER, H .J.; SIDDIQI, M.Y.; GLASS, A.D.M. AtAMT1 gene expression and $\mathrm{NH} 4+$ uptake in roots of Arabdopsis thaliana: evidence for regulation by root glutamine levels. Plant Journal, Oxford, v.19, n. 2, p.143-152, 1999.

REIS JUNIOR, F. B.; MACHADO, C. T. T.; MACHADO, A. T.; SODEK, L. Inoculação de Azospirillum amazonense em dois genótipos de milho sob diferentes regimes de nitrogênio. Revista Brasileira de Ciência do Solo, Campinas, v. 32, n. 3 , p. 1139-1146, 2008.

RUFTY JUNIOR., T. W.; ISRAEL, D. W.; VOLK, R. J.; QIU, J.; TONGMIN, S.A. Phosphate regulation of nitrate assimilation in soybean. Journal of Experimental Botany, Oxford, v. 44, n. 5, p. 879-891, 1993.
RUIZ, H. A.; FERNANDES FILHO, E. I. Cinética: software para estimar as constantes Vmáx e $\mathrm{K}_{\mathrm{M}}$ da equação de Michaelis-Menten. In: REUNIÃO BRASILEIRA DE FERTILIDADE DO SOLO E NUTRIÇÃO DE PLANTAS, n. 10., 1992, Piracicaba. Anais... Piracicaba: Sociedade Brasileira de Ciência do Solo, 1992. p. 124125. (Série Técnico-Científica, 180).

RUIZ, H. Estimativa dos parâmetros cinéticos $\mathrm{Km}$ e Vmáx por uma aproximação gráfico - matemática. Revista Ceres, Viçosa, v.32, n. 179, p.79-84, 1985.

SHELDEN, M. C.; DONG, B.; DE BRUCHELLES, G.; TREVASKIS, B.; WHELAN, J.; RYAN, P. R.; HOWITT, S. M.; UDVARD, N. K. Arabdopsis ammonium transporters AT AMTI:1 and AT AMT1:2 have different biochemical properties and functional roles. Plant and Soil, Amsterdam, v. 231, n. 1, p.151-160, 2001.

TAYLOR, A. R.; BLOOM, A. J. Ammonium, nitrate and proton fluxes along the maize root. Plant Cell and Environment, Oxford, v.21, n. 12, p.1255-1263, 1998.

TEDESCO, M .J. Extração simultânea de N, P, K, Ca e $\mathrm{Mg}$ em tecidos de plantas por digestão com $\mathrm{H}_{2} \mathrm{O}_{2}-\mathrm{H}_{2} \mathrm{SO}_{4}$. Porto Alegre: UFRGS, 1982. (Informativo Interno, n. 01/82).

ULLRICH, W. R.; LARSSON, C. M.; LESCH, S.; NOVACKY, A. Ammonium uptake in Lemna gibba G1, related membrana potential changes and inhibition of onion uptake. Plant Physiology, Berthesda, v.61, n.10, p. 369-376, 1984.

WANG, M. Y.; SIDDIQI, M. Y.; RUTH, T. J.; GLASS, A. D. M. Ammonium uptake by rice roots. II. Kinetics of ${ }^{13} \mathrm{NH}_{4}^{+}$influx across the plasmalemma. Plant Physiology, Bethesda, v.103, n. 1, p.1259-1267, 1993.

WIRÉN,N.;GAZZARRINI, S.;GOJON,A.;FROMMER, W. B. The molecular physiology of ammonium uptake and retrieval. Current Opinion in Plant Biology, Oxford, v.3, n. 3, p.254-261, 2000.

YEMM, E. W.; COCKING, E. C. The determination of amino acids with Ninhydrin. Analyst, London, v.80, n. 948, p.209-213, 1955. 